\title{
Effects of Early Childhood Peer Relationships on Adolescent Mental Health: A 6- to 8-Year Follow-Up Study in South Korea
}

\author{
Kyoung Min Shin ${ }^{1}$, Sun-Mi Cho ${ }^{2}$, Yun Mi Shin², and Kyung Soon Park ${ }^{3}$ \\ ${ }^{1}$ Department of Counseling Psychology, Hanyang Cyber University, Seoul, Republic of Korea \\ ${ }^{2}$ Department of Psychiatry \& Behavioral Science, Ajou University School of Medicine, Suwon, Republic of Korea \\ ${ }^{3}$ Seoul Women's University Graduate School of Professional Therapeutic Technology, Seoul, Republic of Korea
}

\begin{abstract}
Objective Peer relationships are one of the important factors in children's development. The present study examines the relationship between the effects of early peer relationships and adolescent psychological adjustment.

Methods The first survey took place from 1998 to 2000, and a follow-up assessment obtained data in 2006, as the original participants reached 13-15 years of age. The first assessment used the Korean version of the Child Behavior Checklist (K-CBCL) and simple questions about peer relationships to evaluate the participants. The follow-up assessment administered the Korean Youth Self Report (KYSR).

Results Children's peer relationships have longitudinal effects on mental health and adjustment. Children who had qualitative peerrelation problems were more likely to exhibit internalizing problems as adolescents.

Conclusion Children who have poor peer relationships might become more vulnerable to emotional problems and social adjustment as adolescents. Psychiatry Investig 2016;13(4):383-388
\end{abstract}

Key Words Child peer relationship, Adolescent adjustment, Longitudinal study, K-CBCL, K-YSR.

\section{INTRODUCTION}

Peer relationships are thought to play an important role in children's development. ${ }^{1,2}$ They provide opportunities for getting acquainted with the social norms and contexts in which capacities for self-control may be tested and refined. ${ }^{3}$ As Johnson noted, "Experiences with peers are not superficial luxuries to be enjoyed by some students and not by others. Studentstudent relationships are an absolute necessity for healthy cognitive and social development and socialization". According to previous studies, between $5 \%$ and $10 \%$ of children experience chronic peer relationship difficulties, such as peer rejection ${ }^{5}$ and peer harassment. ${ }^{6}$ If peers contribute substantially to the socialization of social competence, it follows that

Received: September 1, 2014 Revised: January 22, 2015

Accepted: June 20, 2015 Available online: April 6, 2016

$\triangle$ Correspondence: Sun-Mi Cho, PhD

Department of Psychiatry \& Behavioral Science, Ajou University School of Medicine, 206 World cup-ro, Yeongtong-gu, Suwon 16499, Republic of Korea Tel: +82-31-219-5180, Fax: +82-31-219-5179, E-mail: smcho@ajou.ac.kr

(c) This is an Open Access article distributed under the terms of the Creative Commons Attribution Non-Commercial License (http://creativecommons.org/licenses/bync/3.0) which permits unrestricted non-commercial use, distribution, and reproduction in any medium, provided the original work is properly cited. children who have poor peer relationships might become more vulnerable to later life maladjustment. Specifically, because low-accepted children experience limited opportunities for positive peer interaction, it follows that they would be relatively deprived of opportunities to learn normal, adaptive modes of social conduct and social cognition. ${ }^{7}$

As the importance of peer relationships in the childhood developmental stages increasingly gains more attention, there have been numerous studies regarding the effects of early childhood peer relationships on early adulthood adjustment. Many researchers reported that early peer relationships have a significant correlation with aggressive, delinquent, oppositional, and illegal behaviors. ${ }^{8-11}$ In addition, results have continuously showed that early peer rejection correlates with increased risk for externalizing symptoms. ${ }^{12,13}$ For example, Fergusson and Woodward reported that 9-year-old children with peer relationship problems showed higher possibilities for externalizing problems such as criminal behavior, substance abuse, and suicidal behavior, although there was no observed increase in the risk for depression or anxiety disorder. ${ }^{14}$

On the other hand, some researchers showed that problems in early peer relationships, especially peer rejection, may be 
related to increased risk for internalizing problems such as anxiety and depression. ${ }^{15,16}$ Burks reported that chronically rejected boys are vulnerable to internalizing difficulties. ${ }^{17}$ Hymel argued that withdrawal in kindergarten predicts feelings of depression, loneliness and negative self-worth in later childhood. ${ }^{18}$

Although the effects of early peer relationships on psychological development in adolescents are clear, the findings are inconsistent regarding whether they affects internalizing or externalizing symptoms. Some argue that concluding a simple and direct correlation between peer relationship problems and psychological maladjustment may not be appropriate because underlying behavior tendencies such as aggression may make more direct contributions to peer relationship problems in the future.

Therefore, our research aims to clarify the causal relationship between early peer relationships and adolescent psychological adjustment, and our 6- to 8-year longitudinal study examines not only the longitudinal effects but also the cross-sectional relationships between the effects of early peer relationships and emotional and behavioral problems in childhood.

\section{METHODS}

\section{Participants}

This study was based on the data derived from a prospective study on child psychiatric disorders in Osan, a small city southwest of Seoul, Korea. A baseline of 3,808 first-grade pupils participated in this epidemiological study. The first assessment of research was conducted with teachers' and parents' approval from 1998 to 2000 . With teachers acting as intermediaries, our investigators contacted families through letters that detailed the study's design, explained its objectives and benefits, and gave assurances of confidentiality. The families who agreed to participate provided written consent. With 6- to 8-year follow-ups, the researcher, with parental consent, requested that 5,670 middle school students living in Osan complete a questionnaire. Among the students, 1,821 had participated in the first assessment. The retention rate was $47.8 \%$, and the mean age of the children at the first assessment was 6.85 years $(\mathrm{SD}=0.41)$; at the second assessment, the mean age was 13.75 years $(\mathrm{SD}=1.0)$. Omitted answers were excluded from the analyses, and thus, a total of 1,227 data were used for the analyses. The dropout analyses showed no significant differences with gender.

\section{Methods}

At baseline, the children's parents completed the Korean version of the Child Behavior Checklist (K-CBCL) ${ }^{19}$ regarding their own children. Researchers frequently use this instru- ment to evaluate children's social adjustment and emotional and behavioral problems. The K-CBCL is a parent-report questionnaire, and it has shown satisfactory internal consistency (from 0.57 to 0.86 ) and test-retest reliability (from 0.31 to 0.72 ). Each child was sent home with a K-CBCL to be completed by the parents and collected after 3 to 5 days.

In addition to the K-CBCL, the parents also answered two questions about their own children's peer relationships: "Compared with other children of the same age, how well does your child get along with their peers?" (response options were: $1=$ Bad, $2=$ Average, $3=$ Good), "Approximately how many friends does your child have?”(response options were: $1=0-1$ friend, $2=2-3$ friends, $3=4$ or more friends).

At the 6- to 8-year follow-up, researchers requested that the now adolescent participants complete the Korean version of the Youth Self Report (K-YSR) ${ }^{20}$ questionnaire, which consists of 112 items covering different behavioral and emotional problems. It has an internal consistency ranging from 0.63 to 0.85 and test-retest reliability ranging from 0.11 to 0.72 . KCBCL and K-YSR items are scored to create a total behavior problem score, eight factor-based scores that represent "narrow-band" syndromes (e.g., withdrawn, somatic complaints, anxious/depressed) and two "broad-band" syndromes, internalizing and externalizing. These analyses used internalizing, externalizing and total behavior problems.

\section{Statistical analysis}

First, the $\chi^{2}$ statistic was used to examine whether gender played a role in the number of friends or how intimate the friendship was. Second, the comparisons of the CBCL and YSR raw scores according to number of friends and their intimacy were performed using the Kruskal Wallis test. In addition, Fisher's exact test was used for comparisons of the frequency of over $60 \mathrm{~T}$ scores on the $\mathrm{CBCL}$ and YSR. Because the distributions of our data were not normal and did not have equal variances, the nonparametric method, the Kruskal Wal-

Table 1. Comparison of peer relationships and number of friends by gender

\begin{tabular}{lcccc}
\hline & $\begin{array}{c}\text { Boys } \\
(\mathrm{N}=568)\end{array}$ & $\begin{array}{c}\text { Girls } \\
(\mathrm{N}=662)\end{array}$ & $\chi^{2}$ & $\mathrm{p}$ \\
\hline Peer relationship & & & 0.68 & 0.711 \\
$\quad$ Bad & $10(1.8 \%)$ & $8(1.2 \%)$ & & \\
Average & $203(35.7 \%)$ & $241(36.6 \%)$ & & \\
$\quad$ Good & $355(62.5 \%)$ & $410(62.2 \%)$ & & \\
Number of friends & & & 4.88 & 0.087 \\
$0-1$ & $17(3.0 \%)$ & $36(5.5 \%)$ & & \\
$2-3$ & $222(39.1 \%)$ & $262(39.8 \%)$ & & \\
4 or more & $329(57.9 \%)$ & $361(54.8 \%)$ & & \\
\hline
\end{tabular}


lis and Fisher's exact test were conducted. Third, standard multiple regression analyses were performed with childhood peer relationships, number of friends, and the internalizing, externalizing, and total behavior problem scales of the K-CB$\mathrm{CL}$ as predictors of emotional and behavioral problems at 6- to 8 years later. Lastly, correlations between peer relationships, number of friends, and the K-CBCL and K-YSR subscales were calculated using Pearson's statistic. All statistical tests were two-sided. PASW statistics software version 18.0 was used for the data entry and statistical analyses.

\section{RESULTS}

A p value of less than 0.05 was taken as statistically significant.

According to the $\chi^{2}$-test, gender was not a significant factor in determining the number of friends $\left(\chi^{2}=0.684, p=0.711\right)$ or the intimacy of peer relationships $\left(\chi^{2}=4.879, p=0.87\right)$ (Table 1$)$.

A nonparametric Kruskal Wallis test was conducted to confirm the differences in the $\mathrm{K}-\mathrm{CBCL}$ and YSR raw scores by peer relationships. Internalizing $\left(\chi^{2}=45.950, \mathrm{p}<0.001\right)$, and externalizing $\left(\chi^{2}=23.070, p<0.001\right)$ problems and total KCBCL score $\left(\chi^{2}=46.017, p<0.001\right)$ all showed statistical significance, with better peer relationships corresponding to lower scores. With the K-YSR scores, only the internalizing problems scale showed significant difference $\left(X^{2}=10.366\right.$, $\mathrm{p}=0.006$ ). Children with poor qualitative peer relationships were more likely to exhibit over $60 \mathrm{~T}$ scores on the internalizing $(\mathrm{p}=0.008$, Fisher's exact test) and total $(\mathrm{p}=0.002$, Fisher's exact test) scales of the K-CBCL and the internalizing scale $(\mathrm{p}=0.001$, Fisher's exact test) of the K-YSR (Table 2).

In examining the differences in K-CBCL and K-YSR scores by number of friends, the internalizing $\left(\chi^{2}=26.468, \mathrm{p}<0.001\right)$ and total sum scores $\left(X^{2}=13.335, p=0.001\right)$ on the K-CBCL showed significant differences, whereas no K-YSR scale showed significance. Children with fewer friends were more likely to show over $60 \mathrm{~T}$ scores on the internalizing $(\mathrm{p}<0.001$, Fisher's exact test) and total ( $\mathrm{p}<0.001$, Fisher's exact test) scales of the K-CBCL, but not on the K-YSR (Table 3).

We investigated qualitative and quantitative peer relationship factors in childhood related to adolescents' internalizing and externalizing problems through standard multiple regression analysis. The K-CBCL internalizing and externalizing problems scale scores were chosen as the independent variables for the multiple regression analyses to control for childhood emotional and behavior problems. Analysis showed that qualitative peer relationships at age 7 independently predicted internalizing problems $(\beta=-1.350, p=0.009)$ and total

Table 2. Comparison of average K-CBCL and K-YSR scores with peer-relationship groups

\begin{tabular}{|c|c|c|c|c|}
\hline & $\mathrm{Bad}$ & Average & Good & Group comparisons \\
\hline \multicolumn{5}{|l|}{$\mathrm{K}-\mathrm{CBCL}$} \\
\hline \multicolumn{5}{|l|}{ Internalizing } \\
\hline Raw score* & $8.89(7.93)$ & $6.01(5.74)$ & $4.79(6.63)$ & $\chi^{2}=45.950, p<0.001$ \\
\hline$\geq 60 \mathrm{~T}, \mathrm{~N}(\%)$ & $3(16.67 \%)$ & $46(10.36 \%)$ & $47(6.14 \%)$ & Fisher's exact test, $\mathrm{p}=0.008$ \\
\hline \multicolumn{5}{|l|}{ Externalizing } \\
\hline Raw score* & $8.06(9.32)$ & $7.28(6.47)$ & $6.08(6.90)$ & $\chi^{2}=23.070, p<0.001$ \\
\hline$\geq 60 \mathrm{~T}, \mathrm{~N}(\%)$ & $2(11.11 \%)$ & $62(13.96 \%)$ & $72(9.41 \%)$ & Fisher's exact test, $\mathrm{p}=0.043$ \\
\hline \multicolumn{5}{|l|}{ Total score } \\
\hline Raw score* & $29.78(28.32)$ & $23.23(20.10)$ & $19.03(23.80)$ & $\chi^{2}=46.017, p<0.001$ \\
\hline$\geq 60 \mathrm{~T}, \mathrm{~N}(\%)$ & $3(16.67 \%)$ & $55(12.39 \%)$ & $53(6.93 \%)$ & Fisher's exact test, $\mathrm{p}=0.002$ \\
\hline \multicolumn{5}{|l|}{ K-YSR } \\
\hline \multicolumn{5}{|l|}{ Internalizing } \\
\hline Raw score* & $16.28(8.86)$ & $14.59(9.04)$ & $13.11(8.69)$ & $\chi^{2}=10.366, p=0.006$ \\
\hline$\geq 60 \mathrm{~T}, \mathrm{~N}(\%)$ & $6(33.33 \%)$ & $93(20.95 \%)$ & $107(13.99)$ & Fisher's exact test, $\mathrm{p}=0.001$ \\
\hline \multicolumn{5}{|l|}{ Externalizing } \\
\hline Raw score* & $14.28(5.94)$ & $12.58(6.87)$ & $12.35(6.04)$ & $\chi^{2}=1.994, p=0.369$ \\
\hline$\geq 60 \mathrm{~T}, \mathrm{~N}(\%)$ & $4(22.22 \%)$ & $102(22.97 \%)$ & $160(20.92 \%)$ & Fisher's exact test, $\mathrm{p}=0.692$ \\
\hline \multicolumn{5}{|l|}{ Total score } \\
\hline Raw score* & $47.61(21.20)$ & $44.63(22.10)$ & $41.81(20.63)$ & $\chi^{2}=5.659, p=0.059$ \\
\hline$\geq 60 \mathrm{~T}, \mathrm{~N}(\%)$ & $6(33.33 \%)$ & $99(22.71 \%)$ & $137(18.59 \%)$ & Fisher's exact test, $\mathrm{p}=0.086$ \\
\hline
\end{tabular}

*mean (SD). K-CBCL: Korean version of the Child Behavior Checklist, K-YSR: Korean version of the Youth Self Report 
problems $(\beta=-2.580, \mathrm{p}=0.035) 6-8$ years later. The regression model showed $0.9 \%$ and $0.7 \%$ explanatory power regarding the internalizing problems $\left(\mathrm{R}^{2}=0.009, \mathrm{p}=0.011\right)$ and total problems $\left(\mathrm{R}^{2}=0.007, \mathrm{p}=0.041\right)$ (Table 4$)$.

Correlations between qualitative and quantitative peer relationship factors and the K-CBCL and K-YSR subscales are presented in Table 5. The majority of K-CBCL subscales were significantly associated with peer relationships and number of friends. Qualitative peer relationships also showed correlations with the majority of K-YSR subscales. On the other hand, quantitative peer relationships were significantly correlated only with withdrawn $(\mathrm{r}=-0.071, \mathrm{p}=0.013)$ and social

Table 3. Comparison of average K-CBCL and K-YSR scores with number of friends

\begin{tabular}{|c|c|c|c|c|}
\hline & $0-1$ friend & $2-3$ friends & $\geq 4$ friends & Group comparisons \\
\hline \multicolumn{5}{|l|}{$\mathrm{K}-\mathrm{CBCL}$} \\
\hline \multicolumn{5}{|l|}{ Internalizing } \\
\hline Raw score* & $7.83(9.47)$ & $6.34(7.41)$ & $4.36(5.00)$ & $\chi^{2}=26.468, p<0.001$ \\
\hline$\geq 60 \mathrm{~T}, \mathrm{~N}(\%)$ & $8(15.09 \%)$ & $58(11.98 \%)$ & $30(4.35 \%)$ & Fisher's exact test, $\mathrm{p}<0.001$ \\
\hline \multicolumn{5}{|l|}{ Externalizing } \\
\hline Raw score* & $8.09(9.25)$ & $7.11(7.81)$ & $6.02(5.71)$ & $\chi^{2}=2.389, p=0.303$ \\
\hline$\geq 60 \mathrm{~T}, \mathrm{~N}(\%)$ & $6(11.32 \%)$ & $63(13.02 \%)$ & $67(9.71 \%)$ & Fisher's exact test, $\mathrm{p}=0.204$ \\
\hline \multicolumn{5}{|l|}{ Total score } \\
\hline Raw score* & $29.09(34.89)$ & $23.73(26.48)$ & $17.94(17.72)$ & $\chi^{2}=13.335, p=0.001$ \\
\hline$\geq 60 \mathrm{~T}, \mathrm{~N}(\%)$ & $8(15.09 \%)$ & $64(13.22 \%)$ & $39(5.65 \%)$ & Fisher's exact test, $\mathrm{p}<0.001$ \\
\hline \multicolumn{5}{|l|}{ K-YSR } \\
\hline \multicolumn{5}{|l|}{ Internalizing } \\
\hline Raw score* & $15.04(9.77)$ & $13.99(9.01)$ & $13.38(8.65)$ & $\chi^{2}=1.722, p=0.423$ \\
\hline$\geq 60 \mathrm{~T}, \mathrm{~N}(\%)$ & $13(24.53 \%)$ & $86(17.77 \%)$ & $107(15.51 \%)$ & Fisher's exact test, $\mathrm{p}=0.183$ \\
\hline \multicolumn{5}{|l|}{ Externalizing } \\
\hline Raw score* & $10.85(6.47)$ & $12.69(6.54)$ & $12.42(6.19)$ & $\chi^{2}=4.775, p=0.092$ \\
\hline$\geq 60 \mathrm{~T}, \mathrm{~N}(\%)$ & $9(16.98 \%)$ & $107(22.11 \%)$ & $150(21.74 \%)$ & Fisher's exact test, $\mathrm{p}=0.733$ \\
\hline \multicolumn{5}{|l|}{ Total score } \\
\hline Raw score* & $42.53(21.66)$ & $43.98(21.55)$ & $42.19(20.94)$ & $\chi^{2}=1.758, p=0.415$ \\
\hline$\geq 60 \mathrm{~T}, \mathrm{~N}(\%)$ & $9(16.98 \%)$ & $96(20.43 \%)$ & $137(20.51 \%)$ & Fisher's exact test, $p=0.869$ \\
\hline
\end{tabular}

Table 4. Variables identified by standard multiple regression analysis as predicting K-YSR internalizing, externalizing and total problem scores

\begin{tabular}{|c|c|c|c|c|}
\hline Predictors & $\beta$ & $\mathrm{F}$ & $\mathrm{R}^{2}$ & Adjusted $\mathrm{R}^{2}$ \\
\hline \multicolumn{5}{|l|}{ Internalizing } \\
\hline Peer relationships & $-1.350 * *$ & $3.758^{*}$ & 0.009 & 0.007 \\
\hline Number of friends & -0.233 & & & \\
\hline Internalizing score of $\mathrm{K}-\mathrm{CBCL}$ & 0.047 & & & \\
\hline \multicolumn{5}{|l|}{ Externalizing } \\
\hline Peer relationships & -0.415 & 1.823 & 0.004 & 0.002 \\
\hline Number of friends & 0.312 & & & \\
\hline Externalizing score of K-CBCL & 0.051 & & & \\
\hline \multicolumn{5}{|l|}{ Total problems } \\
\hline Peer relationships & $-2.580^{*}$ & $2.761^{*}$ & 0.007 & 0.004 \\
\hline Number of friends & -0.216 & & & \\
\hline Total score of CBCL & 0.041 & & & \\
\hline
\end{tabular}

${ }^{*} \mathrm{p}<0.05,{ }^{*} \mathrm{p}<0.01$. K-CBCL: Korean version of the Child Behavior Checklist, K-YSR: Korean version of the Youth Self Report 
problem $(\mathrm{r}=-0.083, \mathrm{p}=0.003)$ subscales of K-YSR.

\section{DISCUSSION}

This study attempted to understand the emotional and behavior effects of childhood peer relationships through a 6- to 8 year longitudinal study. To further clarify the relationship between childhood peer relationships and adolescent acclimation, the study observed not only the emotional and behavioral problems during adolescence, but also childhood adjustment. The conclusion is as follows:

Firstly, childhood peer relationships are significantly associated with problems regarding emotion, behavior, and adjustment. Specifically, children with good peer- relations are mentally healthy and adapt well, whereas children who do not have good peer- relations are more prone to problems in those areas. Put in another way, children who are mentally and behaviorally healthy are more likely to have good peer relationships. Previous researches have also shown that internalizing problems, including social shriveling and lack of socialization, and even externalizing problems, such as aggressiveness, excessive activeness, and oppositional tendency, are closely related to difficulties in peerrelationships. ${ }^{21-24}$ This study also showed a cross-sectional relationship between peer relationships, in both the qualitative and the quantitative senses, and internalizing and externalizing problem during childhood.

Secondly, adolescents who had peer- relation problems as children were more likely to exhibit internalizing problems. At the baseline assessment, both internalizing and externalizing problems in childhood were associated with early peer relationships. However, at the follow-up assessment, only internalizing problem correlated with early peer relationships. This result implies that childhood peer-relations are highly influential to adolescent internalizing problems including shyness/isolated behavior, anxiety, depression, and physical problems and can even control the emotional and behavioral characteristics during childhood. This finding is consistent with previous studies that reported that students who have been rejected by their peers or who have peer relation problems feel a high degree of solitude, social avoidance and depression. ${ }^{16,25}$ On the other hand, other researchers have showed that early peer rejection increased the risk for externalizing problems including aggressive, delinquent and oppositional behaviors. ${ }^{8-13}$ Although it is unclear whether early peer relationships affect internalizing problems or externalizing problems, the effects of early peer relationships on psychological development are prominent. Among them, Coie et al. reported that childhood peer social status predicted parent-reported externalized and internalized disorders and self-reported internalized disorders. The authors also highlighted that the patterns of connection between the predictor and outcome variables differed by source of information. ${ }^{9}$ In our study, peer relationships seemed to be related to self-reported internalizing rather than externalizing problems.

Third, qualitative peer relationships appear to be more important than quantitative relationships in predicting future emotional adjustment problems. However, correlation analysis showed significant associations between number of friends and the K-YSR withdrawn and social problem subscales. Regarding the fact that these two subscales measure unsocial aspects, number of friends during childhood is highly correlated with developing social skills and understanding social norms later on. Bronfenbrenner claimed that both qualitative and quantitative peer-relationship measures plays an important role in child development and social adjustment. ${ }^{26} \mathrm{Al}-$ though our results showed that qualitative peer-relationships in childhood are more pertinent to a variety of emotional and behavioral adjustment problems, the quantitative factor also plays an important role in developing social adjustment skills. Therefore, it seems important to evaluate both the quantitative and the qualitative in predicting future adjustment ability. This finding agrees with previous studies. ${ }^{27,28}$

Table 5. Correlations between qualitative and quantitative peer relationships and K-CBCL/K-YSR subscale scores

\begin{tabular}{|c|c|c|c|c|}
\hline & \multicolumn{2}{|c|}{ K-CBCL } & \multicolumn{2}{|c|}{ K-YSR } \\
\hline & Peer relationships & Number of friends & Peer relationships & Number of friends \\
\hline Withdrawn & $-0.140^{* *}$ & $-0.202^{* *}$ & $-0.068^{*}$ & $-0.071^{*}$ \\
\hline Somatic Complaints & -0.029 & $-0.114^{* *}$ & $-0.063^{*}$ & -0.021 \\
\hline Anxious/Depressed & $-0.113^{* *}$ & $-0.146^{* *}$ & $-0.084^{* *}$ & -0.037 \\
\hline Social Problems & $-0.185^{* *}$ & $-0.224^{* *}$ & $-0.074^{* *}$ & $-0.083^{* *}$ \\
\hline Thought Problems & -0.016 & $-0.115^{* *}$ & -0.024 & -0.008 \\
\hline Attention Problems & $-0.128^{* *}$ & $-0.144^{* *}$ & $-0.067^{*}$ & -0.049 \\
\hline Delinquent Behavior & -0.025 & $-0.105^{* *}$ & -0.031 & -0.027 \\
\hline Aggressive Behavior & $-0.110^{* *}$ & $-0.076^{* *}$ & -0.026 & 0.024 \\
\hline
\end{tabular}

${ }^{*} \mathrm{p}<0.05,{ }^{* *} \mathrm{p}<0.01$. K-CBCL: Korean version of the Child Behavior Checklist, K-YSR: Korean version of the Youth Self Report 
The present study has several limitations. First, only $47.8 \%$ of the original subjects participated in the follow-up assessment. Second, the intervals between the first assessment and the follow-up assessments were not consistent. They varied between 6 and 8 years. Additionally, the findings regarding peer relationships, number of friends and childhood behavioral and emotional problems relied on self-report information. Moreover, as part of an epidemiological study on child psychiatric disorders in Osan, this study only presented one question that evaluated peer relationships and number of friends during childhood, which is perhaps not the most detailed of measures. In addition, the information source differed between the assessments: parents completed the first survey, but participants completed the follow-up survey themselves. Thus, person-to-person interviews with structured formats should be featured in a future study to ensure objective and consistent data.

Despite these limitations, the strength of this study is that it is a community-based longitudinal study with a large sample size for investigating the relationship between early peer relationships and adolescent psychological adjustment. In conclusion, this study suggests that early peer relationships, particularly as assessed qualitatively, are the most important predictor of internalizing problems among adolescents. One important implication that derives from this study is that parents, teachers, and early childhood educators should monitor young children's early social interactions as a potential window into their psychological adjustment and well-being. In addition, peer groups may provide important contexts for early intervention or prevention to effectively increase emotional adjustment in children and adolescents.

\section{REFERENCES}

1. Asher SR, Coie JD. Peer Rejection in Childhood. New York: Cambridge University Press; 1990.

2. Hartup WW. The company they keep: friendships and their developmental significance. Child Dev 1996;67:1-13.

3. Boivin M. The origin of peer relationship difficulties in early childhood and their impact on children's psychosocial adjustment and development. Encyclopedia on early childhood development 2005. Available at: http://www.child-encycolpedia.com/documents/BoivinANGxp. pdf. Accessed October 13, 2011.

4. Johnson DW. Group Processes: Influences of Student-Student Interaction on School Outcomes. In: McMillan JH, Editor. Social Psychology of School Learning. New York: Academic Press, 1980, p. 123-168.

5. Coie JD, Dodge KA. Continuities and changes in children's social status: A five-year longitudinal study. Merrill Palmer Q 1983;29:261-281.

6. Perry DG, Kusel SJ, Perry LC. Victims of peer aggression. Dev Psychol 1988;24:807-814.

7. Parker JG, Asher SR. Peer relations and later personal adjustment: are low-accepted children at risk? Psychol Bull 1987;102:357-389.

8. Bagwell CL, Newcomb AF, Bukowski WM. Preadolescent friendship and peer rejection as predictors of adult adjustment. Child Dev 1998; 69:140-153.

9. Coie JD, Lochman JE, Terry R, Hyman C. Predicting early adolescent disorder from childhood aggression and peer rejection. J Consult Clin Psychol 1992;60:783-792.

10. Coie J, Terry R, Lenox K, Lachman J, Hyman C. Childhood peer rejection and aggression as predictors of stable patterns of adolescent disorder. Dev Psychopathol 1995;7:697-713.

11. Kupersmidt JB, Coie JD. Preadolescent peer status, aggression, and school adjustment as predictors of externalizing problems in adolescence. Child Dev 1990;61:1350-1362.

12. Prinstein MJ, Gillessen AHN. Forms and functions of adolescent peer aggression associated with high levels of peer status. Merrill Palmer Q 2003;49:310-342.

13. Lewin LM, Davis B, Hops H. Childhood social predictors of adolescent antisocial behavior: Gender differences in predictive accuracy and efficacy. J Abnorm Child Psychol 1999;27:277-292.

14. Fergusson DM, Woodward LJ, Horwood LJ. Childhood peer relationship problems and young people's involvement with deviant peers in adolescence. J Abnorm Child Psychol 1999;27:357-369.

15. Gazelle H, Ladd GW. Anxious solitude and peer exclusion: a diathesisstress model of internalizing trajectories in childhood. Child Dev 2003; 74:257-278.

16. Keily MK, Bates JE, Dodge KA, Pettit GS. A cross-domain growth analysis: externalizing and internalizing behaviors during 8 years of childhood. J Abnorm Child Psychol 2000;28:161-179.

17. Burks VS, Dodge KA, Price JM. Models of internalizing outcomes of early rejection. Dev Psychopathol 1995;7:683-695.

18. Hymel S, Rubin K, Rowden L, LeMare L. Children's peer relationships: longitudinal predictions of internalizing and externalizing problems from middle to late childhood. Child Dev 1990;61:2004-2021.

19. Oh K, Hong K, Lee H, Ha E. K-CBCL. Seoul: Chung Ang Aptitude Publishing Co; 1997.

20. Oh K, Ha E, Lee H, Hong K. K-YSR. Seoul: Chung Ang Aptitude Publishing Co; 2001.

21. Kim YK, Lee OK. The effects of peer relations on psychosocial adjustments and behavior characteristics in children and young adolescents. Korean J Psychol: Dev 2001;14:65-82.

22. Crick NR, Casas JF, Ku HC. Relational and physical forms of peer victimization in preschool. Dev Psychol 1999;35:376-385.

23. Landau S, Moore LA. Social skill deficits in children with attentiondeficit hyperactivity disorder. Sch Psychol Rev 1991;20:235-251.

24. Newcomb AF, Bukowski WM, Pattee L. Children's peer relations: a meta-analytic review of popular, rejected, neglected, controversial, and average sociometric status. Psychol Bull 1993;113:99-128.

25. Crick NR, Ladd GW. Children's perceptions of their peer experiences: Attributions, loneliness, social anxiety, and social avoidance. Dev Psychol 1993;29:244-254.

26. Bronfenbrenner U. Ecological Systems Theory. In: Kazdin A, Editor. Encyclopedia of Psychology. Washington, DC and New York: American Psychological Association and Oxford University Press; 2000, p. 129-133.

27. Bukowski W, Hoza, B. Popularity and Friendship: Issues in Theory, Measurement, and Outcome. In: Berndt TJ, Ladd GW, Editors. Peer Relationships in Child Development. New York: Wiley, 1989, p. 15-45.

28. Hodges EV, Boivin M, Vitaro F, Bukowski WM. The power of friendship: Protection against and escalating cycle of peer victimization. Dev Psychol 1999;35:94-101. 